ESJ Social Sciences

\title{
Actions to Perfect Integrating Evaluation in The Training Of Physical Education Teachers
}

\author{
Isaac Alejandro Aquino Davila, M.A.P.E. \\ Gerardo Joel Arredondo Martell, M.P. \\ Gustavo Alvarez, Mendoza, Dr. \\ Antonio Ornelas Gracián, M.M.
}

Facultad de Ciencias de la Cultura Física y Facultad de Medicina y Ciencias Biomédicas; Universidad Autónoma de Chihuahua, México

Doi:10.19044/esj.2021.v17n12p113

Submitted: 20 February 2021

Accepted: 21 April 2021

Published: 30 April 2021
Copyright 2021 Author(s)

Under Creative Commons BY-NC-ND

4.0 OPEN

ACCESS

Cite As:

Davila, AAI., Martel, AJG., and Gracian, OA. (2021). Actions to Perfect Integrating Evaluation in The Training Of Physical Education Teachers. European Scientific Journal, ESJ,17(12),113.https://doi.org/10.19044/esj.2021.v17n12p113

\section{Abstract}

Experience is shared in the application of actions aimed at improving the training of physical educators. It also highlights the evaluation as a substantial element in the training of the professional of physical culture at the Universidad Autónoma de Chihuahua, Mexico. It takes the evaluation as a didactic category that allows integrating all the elements of the teachinglearning process and in its application to verify the effectiveness of the training process. This paper focuses on the elaboration of didactic actions to improve the professional performance of the Physical Culture of students through evaluations in real contexts. Methodologically, collaborative research was used as a variant of participatory action research and as a case study method. As a significant result, it was possible to elaborate and apply the actions to improve the integrative evaluation, which allows evaluating the integration of all the didactic elements in terms of practical performance.

Keywords: Evaluation, interdisciplinary evaluation, professional performance, teaching, teaching learning. 


\section{Introduction}

The practice of the evaluation places its origins in Imperial China, with emphasis on the tests that were put into practice by introducing several tests of practical and academic skills to combat nepotism in the selection of state officials. According to research conducted by Dupuy and Hechavarria (2017), for similar reasons exams were introduced in the western world in the 19th century. It is also proposed that the school system incorporates several forms of execution to guide students, which in the first half of the twentieth century was related to the way individuals were selected to access the different educational programs.

Even though the pedagogical conceptions about evaluation are linked to the evolution of knowledge over time, it is due to the crisis in education and society that this topic began to give more interest since the second half of the twentieth century (Dupuy \& Hechavarria, 2017).

In recent years, evaluation has been assumed as a didactic component of the teaching-learning process which requires a conception of knowledge integration that allows establishing a connection between the knowledge nodes of various disciplines and sciences.

In relation to the subject, it has been investigated in depth about the necessary teaching competences in the teaching-learning processes, especially linked to university studies of initial Teacher Education. An important group of these professional competences are those related to the subject of evaluation. This includes those that refer to the evaluation of student learning, as well as the evaluation of teaching performance and teaching-learning processes in the classroom (Hernán et al., 2019).

However, the evaluation based on interdisciplinary ensures that students not only put their theories into practice, but also have the space to apply in an integrated way the knowledge of various disciplines acquired during their training to their real performance. On the other hand Dupuy and Hechavarria (2017), Masero et al. (2018), Naranjo (2018), Salazar (2018), among others, affirm that despite the dissimilar research that is carried out on this regard, there are still gaps that gives the assumption that teachers have an insufficient domain of the theoretical-methodological reference on interdisciplinarity.

Based on their study results, they report inadequacies in the methodological treatment of interdisciplinary relationships from the year group, as well as in the use of the potential offered by the subjects for interdisciplinary work. It is scarce to take advantage of the possibilities offered by the interdisciplinary approach to teacher evaluations. As a result, it has not yet become a systematic activity of the teaching-educational process in the Facultad de Ciencias de la Cultura Física. Students have difficulties in relating or integrating knowledge in the solution of different 
teaching situations. Therefore, the development of skills to solve teaching tasks with independence is limited, allowing them to determine the essence, establish links and relationships, and apply knowledge to new situations.

On the other hand, Dupuy and Hechavarria (2017) stated that the groups of years and pedagogical, although they try to respond to the preciseness of the curricula in relation to interdisciplinary evaluations, do not develop methodological activities for this purpose and only raise the knowledge nodes by taking the integrative exam as a reference. This is because interdisciplinary evaluations are not conceived in a systematic way during the whole semester, complicating the completion of the integrative exam. Given this problem, it becomes clear that there is no daily integrative exercise that determines the corresponding bases from each of the subjects taught to integrate the contents in each evaluation exercise.

Students have difficulties in relating or integrating knowledge in the solution of different teaching situations. As a result, the development of skills to independently solve teaching tasks is limited, allowing them to determine the essence, establish links and relationships and apply knowledge of new situations, which constitutes the fundamental problem of this study.

The above mentioned allows us to propose, as an objective, the elaboration of didactic actions to develop the interdisciplinarity in the evaluations of the Licenciatura en Educación Física. Hence, this is aimed at improving the professional performance of the graduates of the Degree in Physical Culture of the Facultad de Ciencias de la Cultura Física de Chihuahua.

Based on the above, it is considered that establishing didactic actions based on interdisciplinarity that takes into account the theory-practice relationship will improve the quality of the teaching-learning process validated in the practical performance of students.

Based on the foregoing, the study is considered important because it guarantees the training of teachers in the development of actions from the evaluation to develop interdisciplinary practices in students. Thus, this would establish the foundation of knowledge on scientific bases, based on the integration of the diversity of knowledge of the different disciplines, in order to promote ways of thinking with independence, creativity, and integrality of the contents that they learn. Also, it would further materialize in the delivery of training units or physical education classes or any other stage of the physical culture where this professional works.

\section{Methodology}

The study adopts the methodological approach of qualitative research based on the in-depth analysis of a case in a natural situation (Soto, 2015). In that sense, it was considered to use the case study as a design and the action 
research method, understood as a reflexive process in which the teacher integrates and participates (Soto, 2015). The main tools used were the semidirected interview, the field diary, the participatory observation, the video recording, and the interdisciplinary reflective dialogue.

To carry out the study, the UACH Facultad de Ciencias de la cultura Física was selected as a workspace. The development of the research procedure allowed us to consistently achieve the objectives of the study, which was developed in three stages:

\section{Analysis and Characterization of Teaching Practice:}

There were 46 class sessions of the subject "Theory and Methodology of Physical Education" taught in the Bachelor of Physical Education. The observation process was carried out by two professors. Its development took place in the first and second semester of the 2016-2017 academic years. Participating students attended the 7th and 8th semesters, respectively, with a frequency of two teaching activities per week. Likewise, these two teachers were interviewed using the ECOE technique (Martínez et al., 2005). The results of this stage served as input to arrive at the design of the interdisciplinary evaluation.

\section{Results of the Teacher Interview}

The focus of the interview was aimed at interdisciplinary evaluation in the performance, planning, execution and control of the physical activity process, and the treatment of the diversity of the teaching process in the classroom.

Seeking to respond to the integrative needs of teachers, the interview focused on ruling out those inadequacies that could hinder the evaluation process. The results are shown in Table 1 below.

Table 1. Interview with teachers

\begin{tabular}{|l|l|l|}
\hline \multicolumn{1}{|c|}{ Categories } & \multicolumn{1}{|c|}{ Criteria } & \multicolumn{1}{c|}{ Results } \\
\hline $\begin{array}{l}\text { Interdisciplinary } \\
\text { evaluation }\end{array}$ & \multicolumn{1}{|c|}{ Integration } & $\begin{array}{l}\text { Content exchange, no } \\
\text { relationship between subjects. }\end{array}$ \\
\hline $\begin{array}{l}\text { Attention to } \\
\text { diversity }\end{array}$ & $\begin{array}{l}\text { Relationship between the } \\
\text { general theory of sport and } \\
\text { the specific one of each }\end{array}$ & $\begin{array}{l}\text { Lack of support resources to } \\
\text { facilitate the scientific } \\
\text { foundation. }\end{array}$ \\
\hline $\begin{array}{l}\text { Teaching link to } \\
\text { practical reality }\end{array}$ & Motivation & $\begin{array}{l}\text { The contents do not respond to } \\
\text { real professional performance. }\end{array}$ \\
\hline
\end{tabular}


The category Interdisciplinary evaluation, integration criteria, showed the judgment of the teachers, who pointed out as the main difficulties of the students, the dosage of the load (volume and intensity ratio), the use of methods (discontinuous and continuous), the development of the activities through play (content-methods relationship), performance independence, and pedagogical communication.

The professors considered the evaluation to lack an interdisciplinary treatment, which makes the training of the student more complex. This is in addition to the fact that the preparation of the professors is totally disciplinary. Despite this, they attach great importance to the integral training of the physical education teacher, arguing that they are aware of the need to enhance this aspect of comprehensive evaluation in students based on the exchange of content of various disciplines in the teaching of physical activity.

They recognize the need for a clear and defined idea to ensure that student learning can meet the demands of the evaluation, so that everything taught acquires meaning and meaning to exercise its interdisciplinary function. This is corroborated when students have to apply their knowledge in practice, not being able to contribute significantly, and when they copy models that they have not generally lived.

The category link of teaching to practical reality, motivational criteria, showed that teachers consider that the evaluation should remain in a general framework, since the specificity is provided by the context in which the student performs. This indicates the segmentation between the general and the particular, pointing out the impossibility of learning the theoreticalmethodological general. In addition, it points out that the singular accentuates the fact that the contents do not respond to real professional performance. This determines the need to establish strategies for teachers to conduct this process in a consistent manner, always in correspondence with their particular requirements and with a more specific orientation on methodological programs.

\section{Design and Implementation of Actions to Improve the Integrative}

Evaluation: A collaborative group was formed. Immediately, the actions were designed and the proposal was initiated by establishing seminars and workshops to achieve proposals for the restructuring of programs. The training program was carried out in 60 hours of guided practice and 40 hours of autonomous practice. The organization of the work of the collaborative group took the form of dyads and triads.

III. Construction and Validation of Actions: They were designed and validated for the development and evaluation of competencies in the area of Physical Education, taking as a unit of analysis the didactic sequence. For the 
construction of the training projects, the results of the analysis of the teaching practice were considered, as well as the interdisciplinary planning approach.

\section{Results}

\section{Characterization of Teaching Practice}

In the analysis of the teaching practice, it was observed that it considers the relationship between the general theoretical and methodological content of the training process, with the specificity of the sport chosen by each student. In that sense, the training oscillates between two opposite poles; the general and the specialized. Thus, it shows that none of them helps in a coherent performance of the teacher in training, which brings with it a partial link between teaching and the reality that the student will face in its future and consequently with the integrative evaluation.

It was found that the teaching tasks are oriented on the basis of the previous experiences that students should have according to the semester they are taking and the subjects prior to the subject Theory and Methodology of Physical Education. In general, there is a theoretical teaching detached from the practical, especially not observed in didactic planning. Elements that support an interdisciplinary approach to the theoretical-methodological elements of the chosen sport shows a separation of practice and content of matter with the reality that hinders the evaluation process.

Regarding teaching, it is evident that the professors observed that they conducted their dissertation on the subject from a physiological approach well above the level of student preparation, thereby causing disinterest and low levels of motivation. There are no spaces for the student to integrate the content into practical action.

As a result of its analysis in this article, the characterization of the teaching practice organizes its results in two dimensions: 1) Documentary analysis of classes prepared by the students, 2) Results of the teacher interview. For its analysis, different categories and criteria are used in each dimension.

In the documentary analysis of classes prepared by students, 54 classes developed by students at the end of the subject Theory and Methodology of Physical Education in the 2015-2016 academic years were analyzed. For its assessment, the following criteria were taken: the interdisciplinary approach during the formulation of the objectives, content selection and methodological indications, and method determination. 
Table 2. Documentary analysis of training plans prepared by the students

\begin{tabular}{|c|c|c|}
\hline Categories & Criteria & Results \\
\hline $\begin{array}{c}\text { Interdisciplinary } \\
\text { evaluation }\end{array}$ & Integration & $\begin{array}{c}\text { Lack of inter-matter } \\
\text { articulation. }\end{array}$ \\
\hline $\begin{array}{c}\text { Theory-practice } \\
\text { relationship }\end{array}$ & Contextualized & $\begin{array}{c}\text { Little relationship between } \\
\text { theory and performance. }\end{array}$ \\
\hline Teaching didactics & $\begin{array}{c}\text { Thematic content } \\
\text { structure }\end{array}$ & $\begin{array}{c}\text { Absence of logical order } \\
\text { applicable to reality. }\end{array}$ \\
\hline
\end{tabular}

The Interdisciplinary Evaluation category, in its integration criteria, shows difficulties in determining the objectives of the class. This shows plans with a poor relationship between the objective and the content of the class, thereby affecting the interdisciplinary foundation, which creates a lack of inter-material articulation.

The results of the theory-practice relationship category, contextualized criterion, showed another important aspect, "the selection of activities", in which a certain bias was perceived. When related to the reality for which it is planned, it is seen from poor correspondence between the volumes established by the students in the class and the class system. The main difficulties are conditioned by the limitations of the students to fundamentally determine the contents to be used in their context, which shows little transfer of theory to practical performance.

The Teaching category of teaching, thematic content structure criteria, showed limitations when sequencing the classes. In this regard, difficulties are evident in establishing the duration of each methodological indication to determine the sequence in the creation of the motor habit.

These difficulties presented are mainly conditioned by the schematics with which the students carry it out. This is largely because students make mistakes in the sequencing of the classes that make up the methodological plan, and they do so with partial correspondence based on the type of activity demanded by the different ages and their contents. Furthermore, the absence of an order is also a perceived logical content applicable to reality.

\section{Construction and Validation of Actions}

The built actions are made up of ten theoretical and practical classes. For this purpose, the teachers were provided with support for the achievement of the evidence of performance and for the gradual construction of each project. 
As a result of the workshops given to the teachers, the actions (guides for the student) were designed. The project is operationalized through the ten didactic sequences, which are described below.

Table 3. Schedule of activities for the application of interdisciplinary evaluation

\begin{tabular}{|l|l|l|l|}
\hline \multicolumn{5}{|c|}{ Contents } \\
\hline 1 & 2 & 3 & 4 \\
\hline $\begin{array}{c}\text { Methodological } \\
\text { system of class } \\
\text { planning }\end{array}$ & $\begin{array}{c}\text { Teaching } \\
\text { principles of } \\
\text { physical } \\
\text { education }\end{array}$ & $\begin{array}{c}\text { Application of } \\
\text { the game method } \\
\text { in real contexts }\end{array}$ & $\begin{array}{c}\text { Interdisciplinary } \\
\text { evaluation in real } \\
\text { contexts }\end{array}$ \\
\hline
\end{tabular}

It shows how the objective of the subject is fulfilled in four class frequencies, likewise, the coherence of the contents is guaranteed. Thus, this allows the establishment of the proposed methodological steps for the derivation of these contents from the general didactics to the specific elements of physical education.

\section{Actions to Improve the Integrating Evaluation}

1. The components of the preparation are identified (technical-tactical, psychological, physical, theoretical, and social), and are seen from the statistical calculation based on the percentages to determine the number of weeks for each period and time or space for evaluation.

2. The relationship of these spaces with the basic law of "bio adaptation" training (biological balance between the processes of synthesis and degeneration) is established based on the determination of activities (contentload-training methods). Approaching from biomechanics, the topics "energy systems" is linked to each objective of each class, as well as the description of joints of each body segment for the demonstration and correction of errors (methodological indications) as progress is made in each stage.

\section{Discussion}

The term "evaluation" refers to a generic concept that is constituted from the semantic point of view in a multiform activity that is consubstantial to any type of action aimed at causing changes in an object, situation or person (Dupuy \& Hechavarria, 2017).

In this sense, among others, Naranjo (2018), Masero et al. (2018), Salazar (2018), and Hernán et al. (2019) agreed that the ultimate purpose of the evaluation processes is to be able to determine the level of congruence between the learning objectives and their achievements. They also need evaluation as a systematic activity that should be integrated into the 
educational process and consequently allows an integrative analysis of the relationship between the results and the learning objectives provided in the subjects and the curriculum.

The evaluation allows the identification of the evolution that the professional in training is reaching, accurately measuring the achievement of the student during the teaching-learning process. This is done so that adjustments, variations, new methods, and means can be made to achieve the proposed objectives.

Therefore, the evaluation is considered as an integrative process that is carried out throughout the training process, permanently during the learning activities, that clarifies the students based on the criteria used to assess their performance. Hence, this makes the process of self-evaluation, its critical and self-critical spirit, more motivating and dynamic such that it assumes from its analysis new ways of learning and becoming the protagonist of its own learning.

In this sense, the idea that the student is a participant in this evaluation process is assumed, since they are placed in a position based on the need to integrate knowledge, values, and feelings in close connection with the objectives and contents that are evaluated.

The previous approach corroborates the need to achieve through the evaluation significant changes that fosters the developer learning. It is a way to achieve the objective of the study, establishes its links with the rest of the components of the teaching process, and has a productive content as long as it corresponds to the objective.

Cañadas et al. (2018) supported this approach by saying that university teachers must apply methodological and evaluative strategies that facilitate strengthening key competencies during training and that these are transferable to their future professional field. Not only must they have an impact on the learning of certain concepts, procedures, etc., but they must allow them to apply them in the classroom. Hence, perpetuating the outdated ways of focusing teaching should be avoided. It has been shown that graduates reproduce the same methodology they received during their training, instead of applying the theories they study at the university. However, this is a fact that justifies the need for students to perceive a real change in their training to subsequently adapt to the needs of the work context. Among these practices, evaluation is presented as a fundamental element for this objective.

The evaluation helps in evaluating the performance that the professional is reaching, and it precisely measures the achievement of the student during the teaching-learning process. This is done so that the adjustments, variations, new methods, and means can be applied to achieve the proposed objectives. 
Therefore, the evaluation in its integrating character is carried out throughout the training process, permanently during the learning activities, using non-traditional forms of evaluation. Consequently, it also help students to know the criteria used to value their performance so as to help them review what they are doing and develop their capacity for self-evaluation, their critical and self-critical spirit.

In this sense, among others, Albear et al. (2016), Díaz et al. (2017), and Calderón and Soler (2016) coincided in addressing the need to promote teaching new ways of assessing based on originality as an element that leads to student motivation and consequently the apprehension of integrative content.

These authors consider evaluation as the stage of the educational process that has a regulatory function that intervenes in the students' relationship with knowledge of teachers with students, of students with each other, and of teachers and parents (Dupuy \& Hechavarria, 2017).

On the other hand, Albear et al. (2016), Dupuy and Hechavarria (2017), and Díaz et al. (2017) considered that evaluation is an interactive process of reflection that results not only to corroborating the achievements made, but it also allows the student to participate in this process of self-evaluation of knowledge, skills, and attitudes.

The evaluation is a process that guarantees the space of analysis in practicing the assimilation and appropriation of the contents taught in teaching, where the fulfillment of the objectives at each stage of the teaching process is measured (planning, evaluation intervention).

The model of the Universidad Autónoma de Chihuahua (UACH) emphasizes teaching based on academic skills and is understood as the ability to mobilize cognitive resources to solve problems (Guzmán \& Marín, 2013).

At the Universidad Autónoma de Chihuahua, this training process is based on an educational model that considers competency-based education. It is also based on philosophical and methodological components that start from the analysis of the professional and educational fields where the career takes place, which allows the building of a broad vision of the profession of the physical educator and the search for the implementation of curricula focused on professional performance. In addition, this helps to maintain a balance between the knowledge, know-how, and being of the individual in training.

A curriculum is organized in such a way that the different competences that make up the career converge in relevant performances based on designs and operationalization of student-centered academic processes, flexibility, and the role of the teacher as facilitator. An educational model identified 
with the opening fosters the academic mobility of students and teachers between programs, academic modalities, and institutions.

The curriculum for the career of Physical Culture is understood as a training process that integrates in the evaluation of the professional skills and the system of values of the career in each student, which must be expressed in their cognitive development through a reflective, critical, and self-critical thinking, as well as creative thinking that leads to an integral procedure. Thus, this makes it possible to educate and train a professional with communicative competencies (Dupuy \& Hechavarria, 2017).

In this sense, Physical Culture students show obstacles in the performance of independent work and its fulfillment (a situation that limits their practical performance), and consequently the existing deficiencies identified in the objective relationship - content - method - evaluation.

The above is reflected based on the insufficient preparation from the perspective of the development of skills, knowledge, motor experience, and values to act in a leading way during their training process, assuming the evaluation as part of said process, based on the lack of systematicity in relation to evaluations of an integrative nature.

In this sense, Fernández (2010) emphasizes that the practice of interdisciplinarity requires that the teachers should learn to communicate, which implies a total modification of the university professor, who must be willing to be more than an expert in a discipline. He should be someone who, in addition to teaching, should become a trainer of subjects or personalities.

In principle, interdisciplinarity fosters the integration of theoretical and practical elements, allows the relationship of logical and analytical thinking of the Educational Teaching Process, as well as the linking of subjects and different disciplines.

On the other hand, Columbié et al. (2017), Dupuy and Hechavarria (2017), Jardaneh (2016), Lenoir (2013), Mendoza (2015), Morales (2017), Santos et al. (2017), Sosa et al. (2017), and Vieites and Caride (2017) agreed that interdisciplinarity in higher education is an important opportunity for students to make connections, raise and find answers to complex situations, and adjust learning in a comprehensive and better organized way that allows them to relate with what they are studying in the different disciplines. This is as a result of a new relationship that exists between the student and the teacher, and based on the training of teachers in interdisciplinary work. Here, he should closely associate theory with practice, which will contribute to creating new structures, new content, and new teaching methods.

These authors made assessments of the behavior in the training process of the Physical Culture and highlighted its importance in the selection of the contents from which these relationships are established. They defined interdisciplinarity operationally as a "didactic process aimed at the approach, 
cooperation and integration of the diversity of knowledge of the different disciplines and sciences in order to promote ways of thinking with independence, creativity and integrality in pedagogical performance".

Therefore, with these analysis, it is facilitated to direct concrete actions that guarantee the students to train and clarify their knowledge in a direct relationship with the praxis, nourish themselves of all the possibilities offered by the utility of the convergence areas according to the experiential contexts and situations, and develop professional skills that enhance their role in their own training.

In this sense, interdisciplinary relationships are defined as: a concept that refers to the interaction between two or more disciplines, the product of which enrich their conceptual frameworks, their procedures, their teaching, and research methodologies (Fragoso et al., 2017).

Interdisciplinary work involves a teaching-learning process where no additional or associated content is proposed, but rather it is necessary to establish connections and relationships in the modes of action, knowledge, skills, rules of conduct, feelings, values and integrity, and permanent change.

Therefore, interdisciplinarity is assumed as links or links of interrelation and cooperation between the objectives, contents, and methods of various disciplines, which the teacher uses to merge the knowledge of the students until it forms integrative skills. These skills can be verified in the process of evaluation with productive character so that they achieve professional skills that allow them to know, think and do in an integrated way.

This highlights the imperative need to enhance interdisciplinary evaluation to achieve the training of more competent professionals with skills that are applicable to real contexts.

Currently, teaching in higher education demands from teachers and students more comprehensive ways of thinking and acting, contributing to the creation of spaces that start from the practice and, depending on it, applying the theoretical knowledge that is shared in the classroom classes. Thus, this determines the development of professional skills that are expressed in the motor behavior of the Physical Culture professional in training.

In this sense, Llano et al. (2016) assume the need for the union of all disciplines or subjects, where interrelations are established between the contents, the methods, and other didactic components. In Llano's opinion, interdisciplinary cognitive nodes (NCI) can also be included within the avenues for the establishment of interdisciplinarity. It is the criterion that NCIs can be established among all didactic components: objectives, contents, methods, organizational forms, teaching, and evaluation means.

However, it also presents obstacles that hinder interdisciplinary work, highlighting that teacher training is disciplinary, so they must break a 
formative paradigm when facing a new way of structuring their activity and interacting with other knowledge in which they do not because they are specialists. For this disciplinary training, they consider their discipline the most important within the curriculum in addition to the fact that the training curricula of professionals have an eminently disciplinary cut and, above all, the lack of experience in interdisciplinary work.

On the other hand, these authors report that interdisciplinarity is a goal never fully achieved and hence should be sought permanently. It is not just a theoretical approach; it is first and foremost a practice. Its perfectibility is carried out in practice and as real experiences of teamwork is found, its possibilities, problems, and limitations are exercised.

The methodological teaching preparation of teachers is crucial in the treatment of interdisciplinarity, since they must know in depth the profile of the graduate, the study plan of the career, the programs, calendar plans, and the organizational forms of teaching subjects in question to face linking and application actions. The debate, the organization, and proper planning of didactic actions to be carried out constitute essential premises to carry out the integration (Valdés et al., 2013).

They also propose the need to ensure that students assimilate new content and that they can integrate them. That is why it is important to define that the student in the teaching process is not only a receiver of concepts, but he must be able to analyze, interpret, and apply them. For this, the teacher through productive teaching methods should encourage and enable their active participation in the learning process.

Dupuy and Hechavarria (2017) pointed out that despite the dissimilar research that is carried out in this regard, there are still gaps that allow us to assume that teachers have insufficient mastery of the theoreticalmethodological reference on interdisciplinarity in the year-of-the-year collective, as well as in the use of the potentials offered by the subjects. Therefore, this results in little use of the possibilities offered by the interdisciplinary approach to teacher evaluations. Nonetheless, it has not yet become a systematic activity of the teaching-educational process in the Faculty of Physical Culture.

In this same order of ideas, it states that interdisciplinarity has been widely studied and the proposals abound from diverse theoretical and methodological references. However, how to integrate knowledge into practice and the essential preparation for it, mainly linked to teachers in the direction of the teaching-learning process, continues to be a priority within the contemporary educational system.

The evaluation offered valuable data based on the results of the research since this was based on the analysis of the study plan, the analytical programs of the subjects, as well as the planning and execution of the 
methodological activities developed in the semester related to interdisciplinary evaluation. It also allows us to assess the interdisciplinary conception of evaluations in the curriculum, the projection of methodological scientific and teaching work with an interdisciplinary approach, and the preparation of the pedagogical collective to assume interdisciplinarity in the evaluation process as a final projection of the teaching-learning process.

In this criterion, aspects of relevance and significance of the contents to be integrated were assumed, which allowed the evaluation process to be perfected. This is based on gaining clarity of the contents they learned, how they achieved their link with others to support decision-making process (the existing procedures), and how to apply them to reality.

\section{Conclusion}

The characterization of the teaching practice makes it possible to identify the main insufficiencies in the daily practice, which gave way to the exchange between teachers. They took as their basis the analysis of their own teaching practice, achieve the design of evaluation actions under the interdisciplinary perspective, generate alternatives for teacher improvement that boosted academic productivity, and provide application spaces in real situations.

The elaboration of didactic actions to improve the professional performance of the student of Physical Culture through a manual of procedures that takes into account the interdisciplinary allowed the close participation with the teachers and managed to assess the orientations of educational practices, guaranteeing that they planned under. In this approach, this process offered tools for the restructuring of the analysis of each topic and revealed the links between the disciplines that are directly related to Physical Education.

The construction of this manual that includes integrative actions guaranteed in the teachers, the exchange of knowledge with the sciences related to physical activity and with other specialists from other areas or sceneries of the Physical Culture, creating spaces for reflective practice that led them to think about interdisciplinary planning and consequently achieve greater preparation and application spaces in real situations.

It is a necessity to reconsider the conception of evaluations in the career of Physical Culture so as to achieve the development of integrative skills in future professionals and with it their training based on academic competencies. 


\section{References}

Albear Caró, F., Hernández Creagh, D., Albear Caró, Z., Pérez García, E., \& Carbonell Noblet, A. (2016). Metodología para la evaluación de la competencia de elaboración de medicamentos en escenarios laborales. Revista Información Cientifica, 95(2), 302-309

Calderón, M.A., Ruiz, J.G., \& Soler, F.B. (2016). La evaluación integradora en función del modo de actuación profesional pedagógico.Didasc@ lia: Didáctica y Educación, 7(5), 33-44

Castejón, F.J., Santos Pastor, M., \& Cañadas, L. (2018). Desarrollo de Competencias Docentes en la Formación Inicial del Profesorado de Educación Física. Relación con los Instrumentos de Evaluación. Estudios pedagógicos (Valdivia),44(2), 111-126

Columbié, R.L., Quesada, M A., \& Hernández, S.F. (2017). La teoría y la interdisciplinariedad en la formación de profesionales de la información en Cuba. Revista PRISMA. COM, (31-35).

Díaz, G.S., Barreda, B.M.B., \& Botello, M.E.G. (2017). La evaluación integradora en el proceso de enseñanza aprendizaje de la didáctica de la biología. Revista Boletín Redipe, 6(8), 49-56

Dupuy, O.C. \& Hechavarria, R.E.R. (2017). Alternativa para la evaluación interdisciplinaria en la cultura física. Revista Magazine de las Ciencias. ISSN 2528-8091, 1(4), 53-64

Fernández, L. (2010). Interdisciplinariedad en la construcción del conocimiento: ¿más allá de Bolonia? Innovación Educativa, 20, 157-166

Fragoso Fragoso, J., Garcés Garcés, B. R., Molina Gómez, A. M., Caminero Chávez, V., Roque Roque, L., \& Espinosa Requesens, I. (2017). An approach to interdisciplinarity from Philosophy. MediSur, 15(1), 56-62

Hernán, E.J.B., Pastor, V.M.L., \& Brunicardi, D.P. (2019). ¿ Por qué hago evaluación formativa y compartida y/o evaluación para el aprendizaje en EF? La influencia de la formación inicial y permanente del profesorado (Why do I do Formative and Share Assessment and/or Assessment For Learning in Physical Education?). Retos: nuevas tendencias en educación fisica, deporte y recreación, (36), 37-43

Jardaneh, S. (2016). Building a Foundation for Goal-Attainment and Problem-Solving in Interdisciplinary Studies: Reimagining Web-Based Core Curriculum through a Classical Lens

Lenoir (2013). Interdisciplinariedad en educación: una síntesis de sus especificidades y actualización. Interdisciplina 1.1

Llano-Arana, L., Gutiérrez-Escobar, M., Stable-Rodríguez, A., NúñezMartínez, M., Masó-Rivero, R., \& Rojas-Rivero, B. (2016). La interdisciplinariedad: una necesidad contemporánea para favorecer el proceso de enseñanza aprendizaje. Medisur [revista en Internet]. 2016 
[citado 2016 Ago 23]; 14(3): [aprox. 7 p.]. Disponible en: http://www.medisur.sld.cu/index.php/medisur/article/view/3289

Marín, R. \& Guzmán, I. (2013). Proyectos Formativos para el desarrollo de Competencias. Chihuahua, México: ReDECA, UACH

Martínez-Clares, P., Martínez-Juárez, M., \& Muñoz-Cantero, J.M. (2008). Formación basada en competencias en educación sanitaria: aproximaciones a enfoques y modelos de competencia. RELIEVE-Revista Electrónica de Investigación y Evaluación Educativa, 14(2)

Masero Moreno, I.C., Camacho Peñalosa, M.E. \& Vázquez Cueto, M.J. (2018). Cómo evaluar conocimientos y competencias en la resolución matemática de problemas en el contexto económico a través de rúbricas. Revista Electrónica Interuniversitaria de Formación del Profesorado, 21(1), 51-64

Mendoza-Díaz, J.E. (2015). Estrategia didáctica para la formación interdisciplinaria del Licenciado en Cultura Física. Revista Podium, 10(1), 34-51

Morales (2017). La gestión del Colectivo de Año para la formación integral del profesional de Cultura Física. Revista Conrado, 12(56). pp. 60-65. Recuperado de http://conrado.ucf.edu.cu/

Naranjo, M.A.G. (2018). Metodología de autoevaluación de la calidad del graduado de Licenciatura en Educación. Estudio de caso. Atenas, 1(41), 3450

Salazar Ascencio, J. (2018). Evaluación de aprendizaje significativo y estilos de aprendizaje: Alcance, propuesta y desafíos en el aula. Tendencias Pedagógicas

Santos Martínez, R., Hidalgo, A., Opizo, Q., Orestes, O., Chaviano Herrera, O., García Ávila, I., \& Valdés Utrera, J.R. (2017). Trabajo metodológico: reclamo para lograr interdisciplinariedad desde el colectivo año de la carrera de Medicina. Edumecentro, 9(1), 175-189.

Sosa, L.A.M., Villazón, Y.V., \& Martínez, M.Y.A. (2017). Guía metodológica para el diseño, ejecución y control de tareas docentes integradoras en Morfofisiología Humana. Revista Finlay, 7(1), 58-63

Soto, M.C. (2015). Experiencias docentes en intervención psicomotriz para el logro de competencias en preescolar. Chihuahua,Chihuahua

Valdés, M.V., Castellon, I.M., Águila, B.A., \& Bermúdez, L.L. (2013). Alternativas de interdisciplinariedad para Morfofisiología y Medicina General Integral en el primer año de Medicina. Edumecentro, 3(1), 19-27 Vieites García, M.F., \& Caride Gómez, J.A. (2017). Creación teatral e interdisciplinariedad en la educación superior: hacia un proyecto formativo integrado en arte dramático. Foro de Educación, 15(22), 1-28. doi: http://dx.doi.org/10.14516/fde.502 